\title{
Terrestrial mollusc records from Xifeng and Luochuan L9 loess strata and their implications for paleoclimatic evolution in the Chinese Loess Plateau during marine Oxygen Isotope Stages 24-22
}

\author{
B. $W \mathbf{u}^{1,2}$ and N. Q. $\mathbf{W u}{ }^{1}$ \\ ${ }^{1}$ Key Laboratory of Cenozoic Geology and Environment, Institute of Geology and Geophysics, Chinese Academy of \\ Sciences, P.O. Box 9825, Beijing, 100029, China \\ ${ }^{2}$ Graduate University of the Chinese Academy of Sciences, Beijing, 100049, China
}

Received: 3 December 2010 - Published in Clim. Past Discuss.: 21 December 2010

Revised: 15 March 2011 - Accepted: 16 March 2011 - Published: 20 April 2011

\begin{abstract}
Marine Isotope Stages 24-22 is a key period of the Mid-Pleistocene Transition, however, its climate variability is still unclear. The coarse-grained loess unit L9, one of the most prominent units in the Chinese loess stratigraphy, yields a high potential terrestrial record of paleoclimatic and paleoenvironmental changes during this period. In this study, two high-resolution terrestrial mollusc records of L9 loess strata from the Xifeng and Luochuan sequences in the Chinese Loess Plateau were analysed. Our mollusc results show that the MIS 24, the early and late parts of MIS 22 were dominated by cold and dry climate. Relatively mild-humid climate occurred in MIS 23 and the middle part of MIS 22. The climatic conditions at Xifeng region were cooler and more unstable compared to Luochuan region. A comparison of mollusc species composition and other proxies of L9 strata (MIS 24-22) with those of L1 loess units (MIS 4-2) indicates that the L9 loess was not deposited under the most severe glacial conditions in Quaternary climate history as suggested in previous studies. Our study shows that climatic conditions in the Loess Plateau during the L9 loess forming period were similar to that of gentle glacials (MIS 24 and MIS 22) and interglacial (MIS 23), as suggested by the marine $\delta^{18} \mathrm{O}$ record. Three cooling fluctuations occurred at $\sim 930 \mathrm{ka}$, $900 \mathrm{ka}$ and $880 \mathrm{ka}$, which might hint to the global "900 ka cooling event". The "900-ka event" in the Loess Plateau does not seem to be a simple long glaciation, but rather several complex climatic fluctuations superposed on a general cooling trend. The uplift of the Tibetan Plateau and the general
\end{abstract}

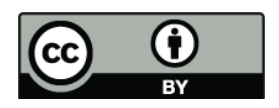

Correspondence to: $\mathrm{B} . \mathrm{Wu}$ (zealot@ustc.edu) cooling experienced by the Earth during this period may have resulted in abundant dust sources and increased dust transport capability, as indicated by increased grain size and the mass accumulation rate of L9 loess.

\section{Introduction}

The Chinese loess sequences have continuously documented the climatic and environmental changes of the past $2.6 \mathrm{Ma}$ (Liu, 1985; Kukla, 1987; Ding et al., 2002). L9 loess, one of the most prominent units among the loess-paleosol sequences, is commonly used as a stratigraphic marker due to its pale colour, coarse texture, loose cementation and huge thickness (Liu, 1985). L9 loess unit is composed of two loess layers and one interbedded paleosol layer, which commonly corresponds to Marine Isotope Stages 24-22 ( 940-860 ka) (Kukla, 1987; Liu et al., 1999; Ding et al., 2002). Previous studies emphasized on field observation and the analysis of physical and chemical proxies and L9 were considered as an indicator of the coldest and driest climate (Liu, 1985; Guo et al., 1998; Lu et al., 2000). Guo et al. (1998) conducted extensive investigations on the properties of L9 loess layer based on paleopedological, geochemical and magnetic susceptibility (MS) variations of three loess-paleosol sections from Xifeng, Changwu and Weinan in the Loess Plateau. Their study suggested that L9 was formed under a semi-desertic climate with strengthened aeolian deposition and the summer monsoon rarely penetrated into the Loess Plateau region. However, marine $\delta^{18} \mathrm{O}$ records show that global ice volume during MIS 24-22 was not as high as those glacials in middle and late Pleistocene, and the amplitude of glacial-interglacial

Published by Copernicus Publications on behalf of the European Geosciences Union. 


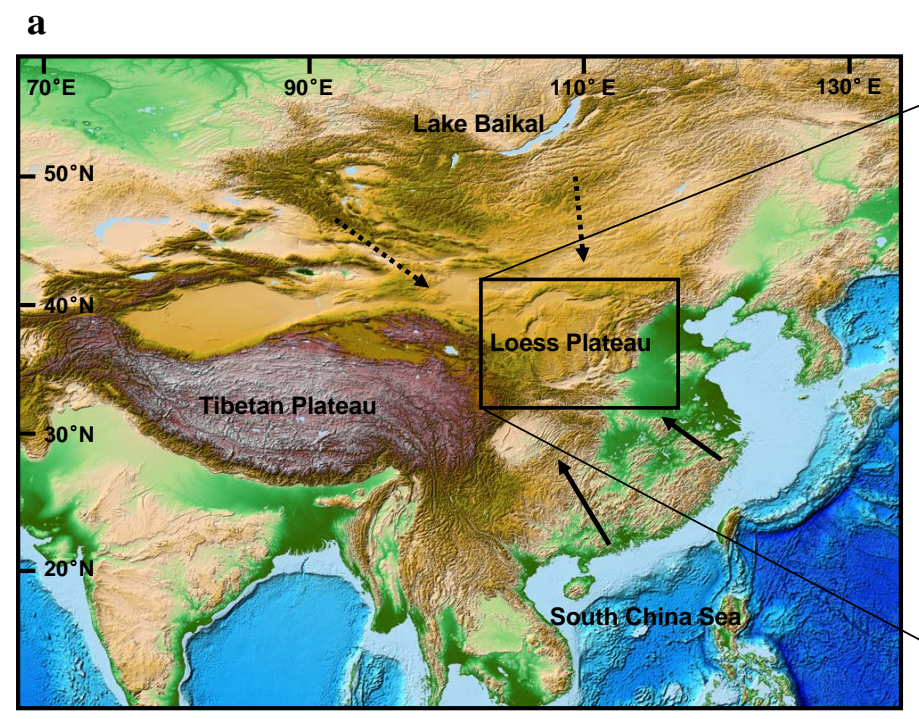

b

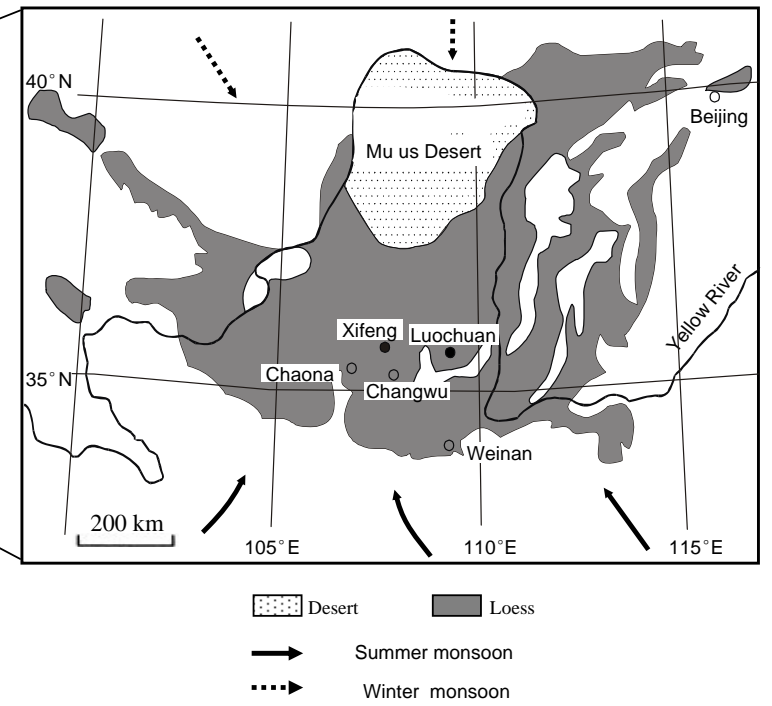

Fig. 1. (a) Map showing the Loess Plateau in the region of High Asia (map modified from NOAA; http://www.ngdc.noaa.gov/mgg/global/ global.html). (b) Sketch map of the Central Chinese Loess Plateau and the location of the studied sites mentioned in the text. The solid arrows indicate the direction of the East Asian summer monsoons, the dashed arrows indicate the pathways of the East Asian winter monsoons.

was relatively small, indicating a weak glaciation (Lisiecki and Raymo, 2005). Thus, it has long been recognized that there was a distinct difference in climatic conditions revealed by terrestrial aeolian records and marine $\delta^{18} \mathrm{O}$ signals during the L9 loess forming period. However, the cause of the extreme climate in the Loess Plateau remains unclear.

As mentioned above, the L9 loess stratigraphy, equivalent to MIS 24-22, was formed at a unique period in Quaternary climate history. It deposited in a transition when the dominant periodicity of global climate changed from $\sim 41$ kyr to $\sim 100$-kyr (i.e. Middle Pleistocene Transition) (Ruddiman et al., 1989; Mudelsee and Schulz, 1997; Raymo et al., 1997; Clark et al., 2006). In addition, the first long glaciation $(\sim 80 \mathrm{kyr})$ of the Pleistocene occurred at $\sim 900 \mathrm{ka}$, when a global cooling event called "900-ka event" was documented in both marine and terrestrial records (Ruddiman et al., 1989; Williams et al., 1997; Schefuss et al., 2004; Zheng et al., 2005; Clark et al., 2006; Bintanja and van de Wal, 2008). However, the amplitude and temporal pattern of this cooling event are different in these records. More investigations are needed to develop a detailed picture of this cooling event to help us understand the temporal and spatial patterns and mechanisms for this event. The thick L9 stratigraphy as a unique terrestrial record provides us with an opportunity to study the behavior of the 900-ka event in East Asia. Not only can it provide information about detailed climate change and the spatial pattern of the semi-arid and semihumid area in the Loess Plateau, it can also reveal the response of the East Asian monsoon system during this period. In this study, we analysed terrestrial mollusc assemblages from two well-known loess-paleosol sequences at Xifeng and Luochuan in the central Loess Plateau to emphasize the following questions: (1) Was the L9 formed under an extremely cold glacial period? (2) Do the climatic conditions, indicated by L9 loess, imply the feature of a regional event or the response of regional climate to a global event? (3) If the latter, how did the loess depositions respond to the global $900 \mathrm{ka}$ cooling event? and (4) How was the exceptionally thick loess deposition formed?

\section{General setting and methods}

The Xifeng $\left(35^{\circ} 46^{\prime} \mathrm{N}, 107^{\circ} 41^{\prime} \mathrm{E}\right)$ and Luochuan $\left(35^{\circ} 45^{\prime} \mathrm{N}\right.$, $109^{\circ} 25^{\prime} \mathrm{E}$ ) loess sequences are located in the central Loess Plateau (Fig. 1). The climate in this study area is characterised by seasonal alternation of the East Asian summer and winter monsoons (Zhang and Liu, 1992). The modern mean annual temperature (MAT) and precipitation (MAP) are $8.3^{\circ} \mathrm{C}$ and $560 \mathrm{~mm}$ in Xifeng, and $9.0-9.2^{\circ} \mathrm{C}$ and $620-$ $660 \mathrm{~mm}$ in Luochuan, respectively.

These two classical loess sections have been intensively investigated (e.g. Heller and Liu, 1982; Liu, 1985; Kukla, 1987; Kukla and An, 1989; Kukla et al., 1990; Porter and An, 1995; Guo et al., 1996, 1998, 2000; Wu et al., 1996, 1999, 2000, 2001, 2007; Rousseau and Wu, 1997, 1999; Lu et al., 2000; Rousseau et al., 2009). In this study, the focus is on the L9 loess stratigraphies of the two loess-paleosol sequences, which were formed during MIS 24-22. Figure 2 shows the correlation of magnetic susceptibility (MS) records from the 


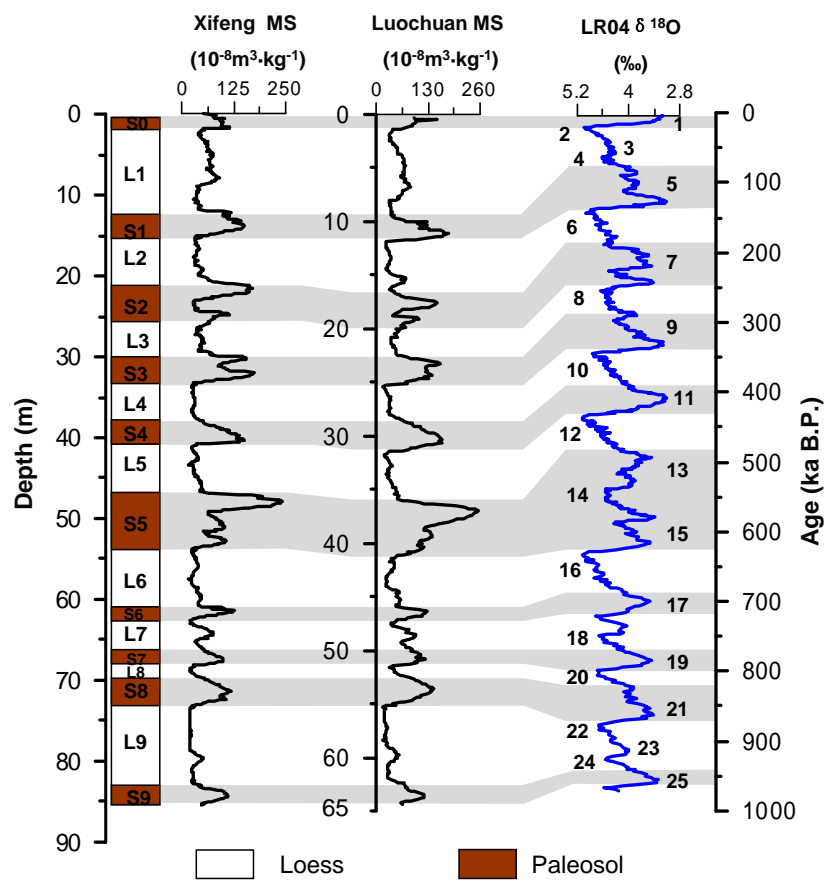

Fig. 2. Magnetic susceptibility (MS) records of the loess-soil sequence of the last $1000 \mathrm{ka}$ from Xifeng and Luochuan and correlation with the LR04 $\delta^{18} \mathrm{O}$ record (Lisiecki and Raymo, 2005). The soil and loess units are labelled following Liu (1985). The land-sea correlation scheme follows Kukla (1987) and Liu et al. (1999).

Xifeng and Luochuan loess-paleosol sequences of the last 1000 ka with the newly compiled LR04 $\delta^{18} \mathrm{O}$ record. The L9 stratigraphy in the Xifeng section is $\sim 10.7 \mathrm{~m}$ in thickness with three layers, i.e. L9LL1 loess, L9SS1 paleosol, and L9LL2 loess from the top down (Kukla and An, 1989; Kukla et al., 1990). The L9 stratigraphy in the Luochan section is $\sim 7.5 \mathrm{~m}$ in thickness with the same three layers as Xifeng section. The L9LL1 and L9LL2 loess correspond to MIS 22 and 24 (Fig. 2), respectively, whereas the L9SS1 paleosol is equivalent to MIS 23 (Liu, 1985; Liu et al., 1999; Ding et al., 2002). The age of the studied two loess sequence was obtained by using the boundaries ages of loess-paleosol sequences (Ding et al., 2002) as age controls, and then interpolation between age controls using the magnetic susceptibility model of Kukla et al. (1990). Although this model was based on some assumptions which are still somewhat contentious (Heller et al., 1993), it remains a working model for obtaining an independent timescale, having been widely used in many long-term loess dating studies (Kukla and An, 1989; Kukla et al., 1990; Liu et al., 1995; Guo et al., 1998, 2000).

A total of 196 samples for the mollusc study were taken from the L9 strata of the two loess sections at $10 \mathrm{~cm}$ interval, which represents an approximate average temporal resolution per sample of $\sim 500-800$ years for loess and $\sim 700$ 1300 years for soil in Xifeng, and $\sim 700-900$ years for loess and $\sim 700-1300$ years for soil in Luochuan. Each sample weighs about $15 \mathrm{~kg}$. All samples were washed and sieved in the field with a mesh diameter of $0.5 \mathrm{~mm}$. The mollusc shells were picked and identified under a binocular microscope. All identifiable remains were considered in the total count of individuals following the method developed by Puisségur (1976).

\section{Results}

\subsection{Fossil mollusc assemblages}

Terrestrial mollusc shells are particularly abundant in the L9 strata of the Xifeng and Luochuan sequences (Fig. 3). Shells have been found in all the sampling levels in both sections. In the Xifeng section, the maximum count $(2151 / 15 \mathrm{~kg}$ shells) is at the bottom of L9SS1 (80.6 m at the depth), whereas the minimum (only 1 individual) is at the top of L9LL1 (74.5 $\mathrm{m}$ at the depth). The average numbers of individuals per sample in the Xifeng section are 529, 1285 and 352 in L9LL2, L9SS1, and L9LL1 units, respectively. In the Luochuan section, the highest value of mollusc shell individuals reaches $4156 / 15 \mathrm{~kg}$ in L9SS1 (59.3 $\mathrm{m}$ at the depth), and the top of L9LL1 (55.3 $\mathrm{m}$ at the depth) just contains one individual (the minimum). Again, more individuals are found in the soil layer (2313/15 kg in L9SS1) than in the loess layers (473/15 kg in L9LL2 and 558/15 kg in L9LL1) at the Luochuan section (Fig. 3). A total of 140461 individuals were identified for the L9 strata of the Xifeng and Luochuan sections.

14 mollusc species were identified in the Xifeng loess section (Fig. 3a). The dominant species includes Vallonia tenera, Vallonia cf. pulchella, Pupilla aeoli, Pupilla cupa, Gastrocopta armigerella and Punctum orphana. Figure 4a shows percentage variations of these species during the interval of MIS 24-22. High percentages of both $V$. tenera and $P$. cupa exhibit during MIS 24 and 22. Three peaks in the percentages of V. tenera (over 50\%) occur at MIS 24, early and late parts of MIS 22. P. aeoli dominates most of MIS 23 (over 60\%) and the middle part of MIS 22 (over 70\%). G. armigerella exhibits maximum counts at the early part of MIS $23(\sim 38 \%)$ and the middle part of MIS $22(\sim 39 \%)$. Both $V$. cf. pulchella and $P$. orphana show a high abundance during MIS 23.

In the Luochuan loess section, 15 mollusc species were identified from the L9 stratigraphy (Fig. 3b). The predominant taxa are $V$. tenera, $V$. cf. pulchella, $P$. aeoli, $P$. cupa, G. armigerella and P. orphana, similar to the Xifeng section. The percentage variations of these six species are shown in Fig. 4b. V. tenera exhibits two main peaks at MIS 24 (over $40 \%$ ) and the early part of MIS 22 (over $30 \%$ ), and P. cupa reaches its highest value at the early part of MIS 22 . High percentages of $P$. aeoli (over 50\%) mainly occur in the early part of MIS 24, MIS 23 and the middle part of MIS 22. $G$. armigerella and $V$. cf. pulchella show relatively sustained abundance during MIS 24-22 except for the boundary of 


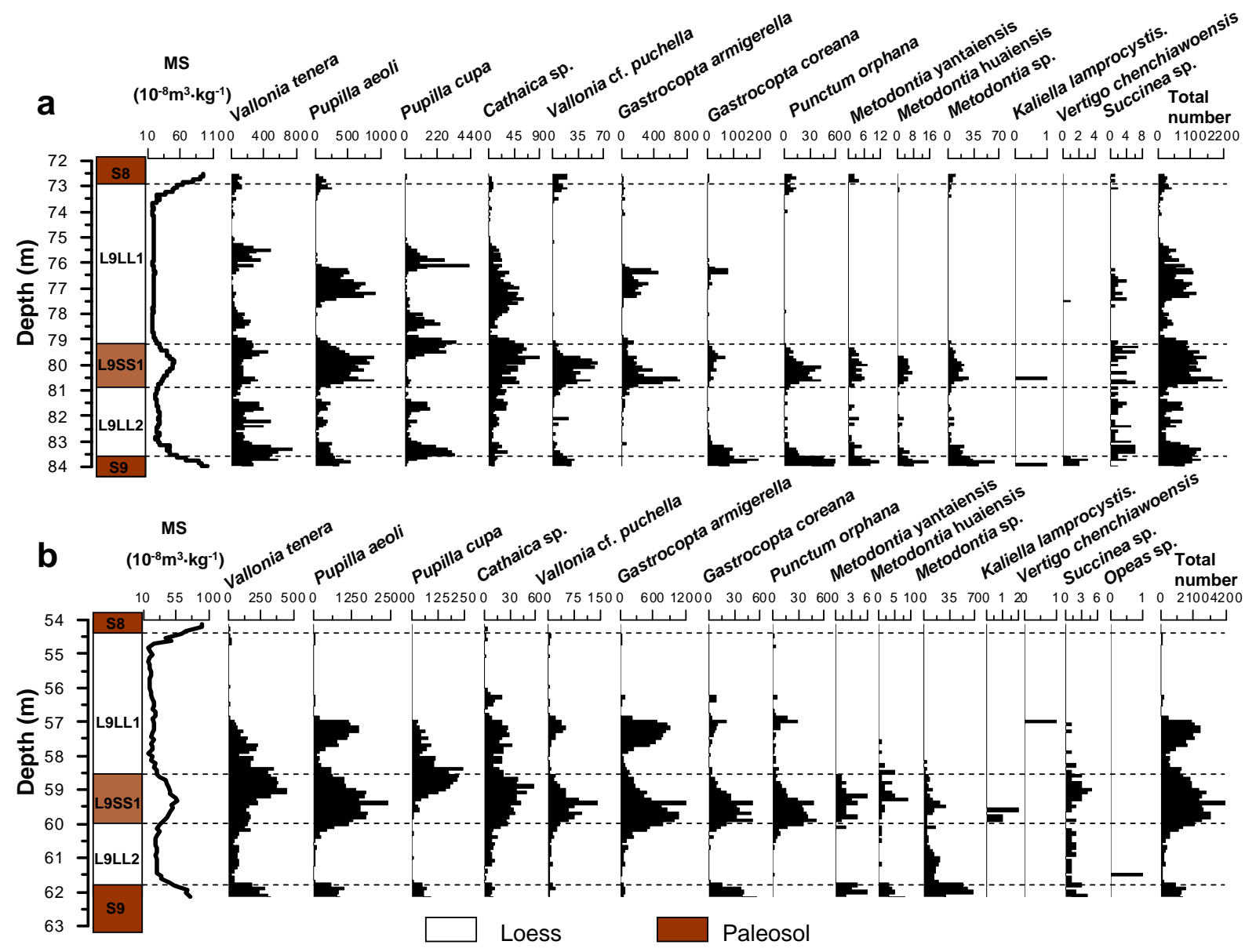

Fig. 3. Variations in mollusc species and magnetic susceptibility in the Xifeng (a) and Luochuan (b) L9 stratigraphies plotted versus depth. The mollusc species are expressed in the absolute abundance (total number of individuals counted per $15 \mathrm{~kg}$ ).

MIS 23 and MIS 22. G. armigerella maintains its high values (over 30\%) during the late part of MIS 24 to the early part of MIS 23, and the most part of MIS 22. P. orphana has low abundance and exhibits its main peak at MIS 23 and the middle part of MIS 22 .

It should be pointed out that a large number of mollusc shells were dissolved in the upper part of L9LL1 (at depths of 73.2-74.6 $\mathrm{m}$ in Xifeng and 54.2-55.8 $\mathrm{m}$ in Luochuan) due to a strong carbonate dissolution as the upper S8 soil formed. This dissolution process largely modified the mollusk faunal compositions in species and individuals. However, the mollusc remains could still provide some information about environmental changes.

The mollusc assemblages of the Xifeng and Luochuan L9 strata can be divided into three ecological groups according to the ecological requirements of those taxa for temperature and moisture (Chen and Gao, 1987; Wu et al., 1996, 1999, 2001; Rousseau and Wu, 1997, 1999). The first one is the cold-aridiphilous group, consisting of V. tenera, P. aeoli and P. cupa. These taxa live in dry and relatively cold regions presently dominated by winter monsoon, and their fossil species are, thus, used as an indicator of winter monsoon (Liu, 1985; Wu et al., 1996; Rousseau and Wu, 1997, 1999). The second one is the thermo-humidiphilous group. The species of this group including G. armigerella and P. orphana favour warm and moist conditions. They are presently distributed in the regions dominated by summer monsoon, and their appearance in the loess stratigraphy indicates a penetration of the summer monsoon into the Loess Plateau region (Wu et al., 2000, 2002). The third one is the coolhumidiphilous group, which contains one species, $V$. cf. pulchella. This taxon lives in relatively cool and wet regions (Chen and Gao, 1987; Wu et al., 1996).

\subsection{Climatic conditions inferred from fossil mollusc assemblages}

The abundant mollusc individuals preserved in the L9 strata in the Xifeng and Luochuan loess sections provide us with an opportunity to investigate climatic and environmental conditions in the Loess Plateau during MIS 24-22 on a more detailed level. Since most of the identified taxa in both sections 


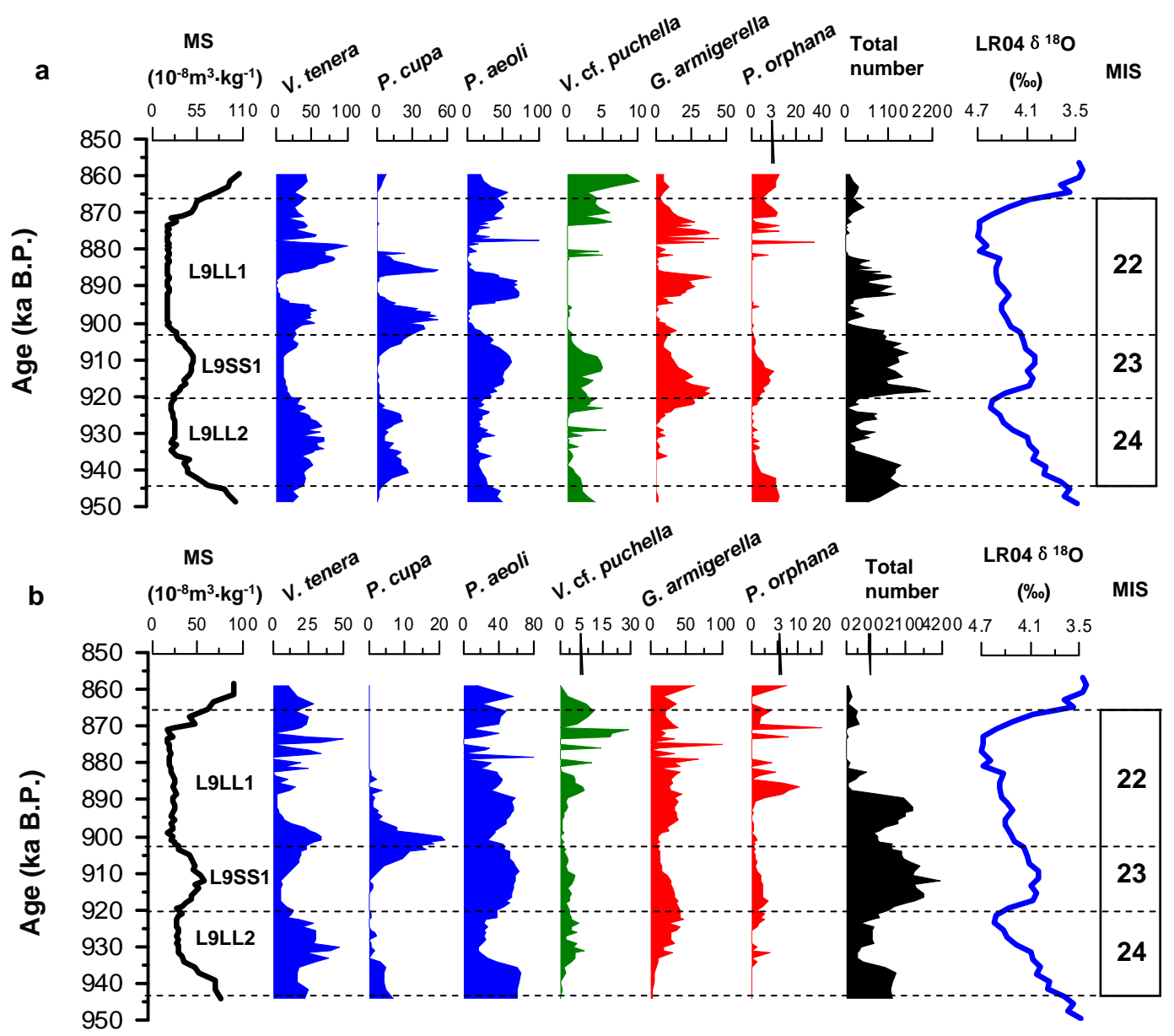

Fig. 4. Variations in the percentages of six mollusc species in the Xifeng (a) and Luochuan (b) loess sequences during MIS 24-22, compared with the variations in magnetic susceptibility and LR04 $\delta^{18} \mathrm{O}$ record (Lisiecki and Raymo, 2005). The three ecological groups are distinguished by colours (blue for cold-aridiphilous, green for cool-humidiphilous and red for thermo-humidiphilous).

have their modern analogs (Liu, 1985; Chen and Gao, 1987; Wu et al., 2002, 2007), we can use modern observation data to infer paleoclimatic conditions in the studied area.

As shown in Fig. 4a and b, mollusc fauna in both Xifeng and Luochuan sections were dominated by cold-aridiphilous taxa in L9LL2. Among them, V. tenera is a dominant species. It presently prefers drier and colder ecological environments than other species in the continental interior of northwest China, with optimal ranges of MAT $\left(5.8-10.5^{\circ} \mathrm{C}\right)$ and MAP (200-350 mm) (Chen and Gao, 1987; Wu et al., 2001, 2002, 2007). Its high percentages at MIS 24 (over 67\%) together with abundant $P$. aeoli and P. cupa in the Xifeng section indicate a cold-arid climatic condition, implying a strengthened winter monsoon. Few thermo-humidiphilous taxa such as $G$. armigerella and $P$. orphana during this interval reflect a weak influence of summer monsoon on this region. Meanwhile, the Luochuan region was also dominated by a cold-arid climate, as indicated by a peak value of $V$. tenera (reaches 47\%). However, the abundance of thermo-humidiphilous $G$. armigerella shows an increasing trend upon the middle part of L9LL2 and reaches $40 \%$ at the end, indicating warmer and wetter conditions in the $\mathrm{Lu}-$ ochuan than in the Xifeng region.

During the interglacial of MIS 23, relatively warm-humid conditions prevailed over the Loess Plateau, as evidenced by high values of $G$. armigerella and P. orphana in L9SS1. G. armigerella is a typical thermo-humidiphilous species in modern mollusc assemblages. It prefers a relatively warmhumid environment with MAT and MAP ranges being $~ 5.8-$ $10^{\circ} \mathrm{C}$ and $450-550 \mathrm{~mm}$ (Wu et al., 2007). P. orphana has higher requirements for thermal-hydrologic conditions than $G$. armigerella. It now is mainly distributed in the southeast of China with MAT of $\sim 13-17.5^{\circ} \mathrm{C}$ and MAP of $600-$ $1100 \mathrm{~mm}$ (Chen and Gao, 1987; Wu et al., 2001). The abundance of these two species indicates that the precipitation during MIS 23 was approximately close to modern precipitation conditions in the southeast part of the Loess Plateau, however, the temperature was lower than the present. Moreover, the numbers of snail individuals per sample at this interval reach their highest values through the MIS 24-22 
period (Fig. 3), indicating a distinct amelioration of thermalhydrologic conditions in the Loess Plateau during the interglacial period of MIS 23. However, cold-aridiphilous species $P$. aeoli with MAT and MAP ranges of $\sim 5-10^{\circ} \mathrm{C}$ and 200-500 mm (Chen and Gao, 1987) also shows high abundance at this interval. Though both species of P. aeoli and $G$. armigerella belong to different ecological groups, there is a range of coexistence between their ecological conditions. The high abundances of both species indicate a relatively cool-wet environment. Modern populations, most similar to this assemblage, are associated with MAT of about $6-8{ }^{\circ} \mathrm{C}$ and MAP of about $300-500 \mathrm{~mm}$ (Wu et al., 2007). This suggests that the climatic conditions in the Loess Plateau might be generally mild. In the late part of MIS 23, a rapid cooling trend happened, as indicated by a quick increase in the numbers of $V$. tenera and $P$. cupa in two sections. Meanwhile, $G$. armigerella and $P$. orphana, the thermo-humidiphilous species, decreased rapidly and even vanished.

During MIS 22, the Loess Plateau underwent two obvious cold-dry/warm-wet cycles. Climatic conditions were extremely cold-dry in the early part of MIS 22 (around $\sim 900 \mathrm{ka}$ ), as evidenced by the remarkably high abundance of $V$. tenera and $P$. cupa. The modern analog of this assemblage exists near the northwestern boundary of the Loess Plateau where MAT is $\sim 4-7{ }^{\circ} \mathrm{C}$ and MAP $\sim 200$ $300 \mathrm{~mm}$ (Chen and Gao, 1987). This indicates that both the temperature and precipitation in Xifeng and Luochuan regions at about $900 \mathrm{ka}$ were much lower than nowadays. Moreover, the numbers of individuals, per sample, drop to very low values during this interval, which also reflects severe climatic conditions. In the middle part of MIS 22 (around $890 \mathrm{ka}$ ), climatic conditions tended to be moderate, as shown by marked increases of $G$. armigerella in the Xifeng section and P. orphana in the Luochuan section. However, the high peak of $P$. aeoli at this period still indicates cool conditions somewhat like that in MIS 23. Another cold-dry/warm-wet cycle happened in the late part of MIS 22 ( $885-860 \mathrm{ka})$. Since strong carbonate dissolution dissolved a large number of mollusc shells, the mollusk faunal compositions during this interval were largely modified. However, the remained mollusc individuals can still provide enough information about climate changes. A notable change in mollusc fauna is that the high abundance of $V$. tenera has been replaced by high $G$. armigerella, reflecting that climate changed from cold-dry to warm-wet. This change is more evident in the Xifeng section than in the Luochuan section (Fig. 4a and b).

In summary, the high-resolution mollusc records from the Xifeng and Luochuan L9 loess stratigraphy reveal that the climatic conditions were highly variable in the Loess Plateau during MIS 24-22. The climate in this region during this period experienced a series of changes from cold-dry, mild, shortly cold-dry, cool-wet, cold-dry, to relatively warm-wet conditions.
However, climatic conditions show somewhat the difference between the Xifeng and Luochuan sections. First, the number of mollusc individuals and the abundance of thermohumidiphilous species in the L9 loess stratigraphy are higher in the Luochuan section than the Xifeng section, indicating warmer and wetter climatic conditions at Luochuan. Second, a continuous occurrence of G. armigerella at Luochuan suggests that the East Asian summer monsoon could affect this region during the whole period of MIS 24-22, but it was absent at Xifeng in the three coldest stages $(\sim 930 \mathrm{ka}, 900 \mathrm{ka}$, and $880 \mathrm{ka}$ ) of MIS 24 and MIS 22. Thus, a greater climate gradient might exist in the Loess Plateau at these cold periods than the warm ones. The environmental conditions at Xifeng were more instable and variable than Luochuan.

\section{Discussions}

\subsection{Climatic implications of L9 loess}

In previous studies, L9 loess was suggested as a representative of extremely cold and dry climatic conditions (e.g. Liu, 1985; Guo et al., 1998; Lu et al., 2000). However, marine isotope records show that MIS 24 and 22 are not the most severe glacials in the Quaternary history. Therefore, it has long been argued that loess records might reveal a quite different climatic condition from that indicated by marine isotope records. L9 loess was, thus, ascribed to regional rather than global climate changes (Liu, 1985; Sun and Liu, 2000). Our new mollusc records reveal that severe climatic conditions recorded by L9 loess only occurred at three stages in the Loess Plateau, i.e., at $\sim 930 \mathrm{ka}, 900 \mathrm{ka}$ and $880 \mathrm{ka}$. Climatic conditions during other intervals of MIS 24-22, apart from these three cold periods, were relatively mild, suggesting that L9 loess was not formed under a uniform condition with an extremely cold and dry climate.

Clark et al. (2006) indicated that the climate of MIS 2422 has a pattern similar to that of the last glacial (MIS 42 ). They both have long glaciations consisting of two stadials separated by an interstadial period. A comparison of the L9 and L1 (corresponding to MIS 4-2) loess shows somewhat a similarity between them. For example, they are composed of two loess layers and a subdued paleosol layer, and both of them have great thickness (in Xifeng the thickness of L9 is $\sim 10.7 \mathrm{~m}$ and L1 is $10.2 \mathrm{~m}$; in Luochuan L9 is $\sim 7.5 \mathrm{~m}$ and L1 is $8.5 \mathrm{~m}$ in thickness) and high sedimentation rates (in Xifeng are $\sim 14 \mathrm{~cm} \mathrm{kyr}^{-1}$ in L9 and $17 \mathrm{~cm} \mathrm{kyr}^{-1}$ in L1; in Luochuan are $\sim 10 \mathrm{~cm} \mathrm{kyr}^{-1}$ in L9 and $15 \mathrm{~cm} \mathrm{kyr}^{-1}$ in L1). However, our mollusk records do reveal a significant difference between them. Mollusc assemblages from L9 loess are remarkably different from those of the L1 loess (Wu et al., 1996; Chen and Wu, 2008) (Fig. 5). The former contains less cool-humidiphilous species and more thermo-humidiphilous mollusc species. For example, the mean values of $G$. armigerella are $1.2 \%$ at Xifeng and $0.2 \%$ 


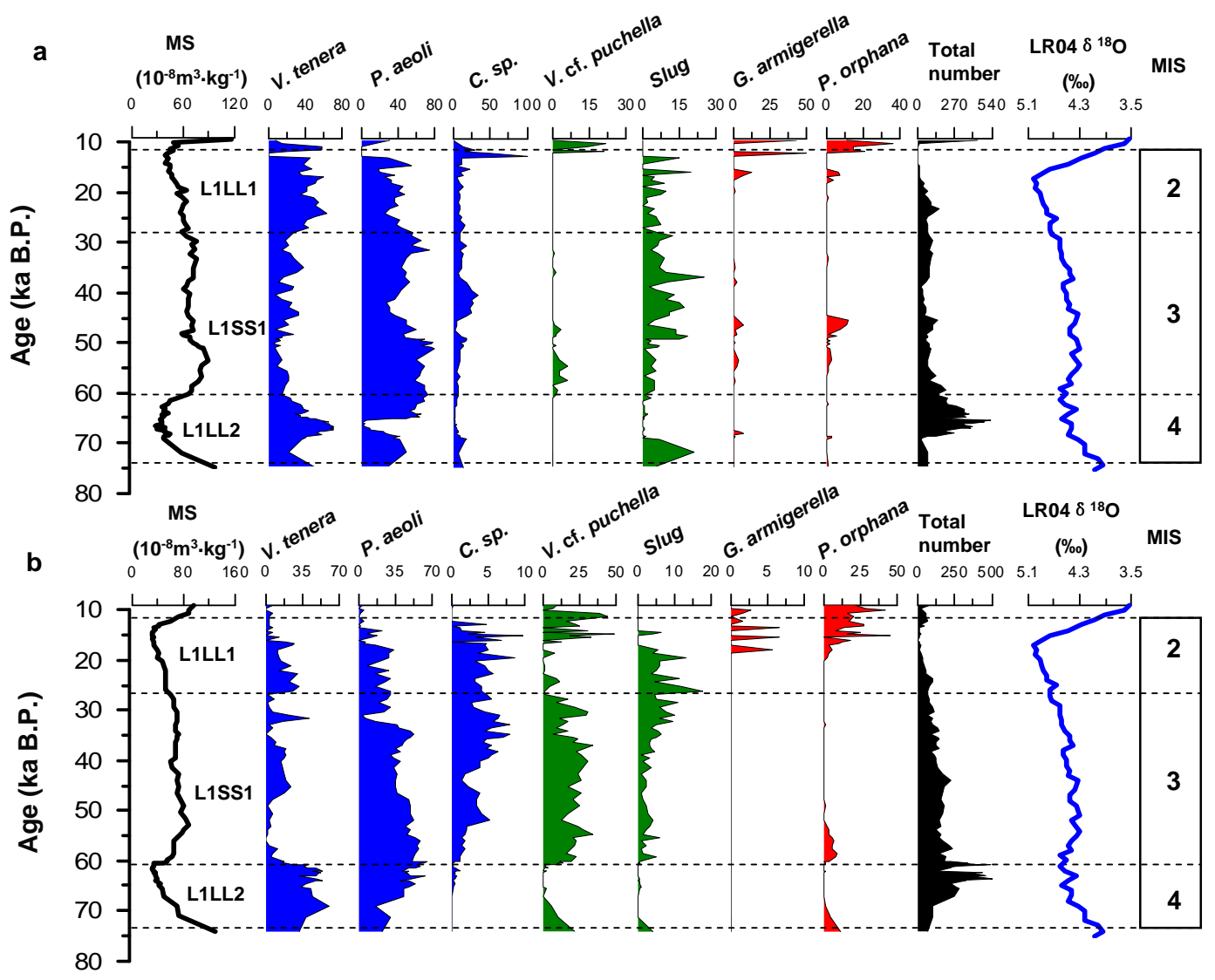

Fig. 5. Variations in percentages of mollusc fossil species from the last glacial (L1) records in the Xifeng (a) (Chen and Wu, 2008) and Luochuan (b) (Wu et al., 1996) loess sequences. The three ecological groups are distinguished by colours (blue for cold-aridiphilous, green for cool-humidiphilous and red for thermo-humidiphilous).

at Luochuan during MIS 4-2, whereas they reach $11 \%$ at Xifeng and 26\% at Luochuan during MIS 24-22 (Fig. 4). The mollusc assemblages during the last glacial indicate that climatic conditions were colder and drier than the MIS 2422 in the Loess Plateau. Figure 6 shows variations in mollusc biomass (mollusc biomass $=$ number of individuals in each sample/(sample vol./sampling thickness)/sedimentation time) during MIS 24-22 and MIS 4-2. Obviously, the mollusc biomass during MIS 24-22 is much higher than that of MIS 4-2, indicating the same fact as revealed by mollusc assemblages. Furthermore, the sedimentation rates are much lower in L9 than L1 at the Xifeng and Luochuan sections (Fig. 7), supporting mollusc results. Additionally, the weathering intensity revealed by the $\mathrm{FeD} / \mathrm{FeT}$ ratio of loess deposits indicates that the L9 loess experienced stronger pedogenesis than L1 (Guo et al., 2000), and a pollen record from Chaona loess sequence in the central Loess Plateau shows that the vegetation during MIS 24-22 was a forest-steppe instead of steppe during the last glacial (Wu et al., 2004). Overall, all these lines of evidence indicate that climatic conditions during L9 loess formation were less severe than those of the last glacial. Therefore, it can be concluded that the L9 loess was not a production of an extremely cold glacial period as suggested by previous studies. In spite of the occurrence of some short cold fluctuations, the climatic conditions recorded by L9 loess are similar to that indicated by marine isotope records. It is characterised by gentle glacials (MIS 24 and 22) and interglacial (MIS 23).

\subsection{The response of $900-\mathrm{ka}$ cooling event in the Loess Plateau}

As mentioned above, a series of significant changes in global climate occurred during MIS 24-22. For example, global ice volume during this period increased by $15 \%$ compared to former glacials (Lisiecki and Raymo, 2005), thus, the first long glaciation $(\sim 80 \mathrm{kyr})$ of the Pleistocene occurred around 900 ka (Jansen et al., 2000; John and Krissek, 2002; Bintanja and van de Wal, 2008). And the sea level reached its lowest at MIS 22 during the interval from MIS 28 to MIS 22 (Kitamura and Kawagoe, 2006). Clark et al. (2006) referred to such cold-dry global climatic conditions as "900-ka event". This global cooling event has been documented in many records (Ruddiman et al., 1989; Clemens et al., 1996; Hodell et al., 
Xifeng

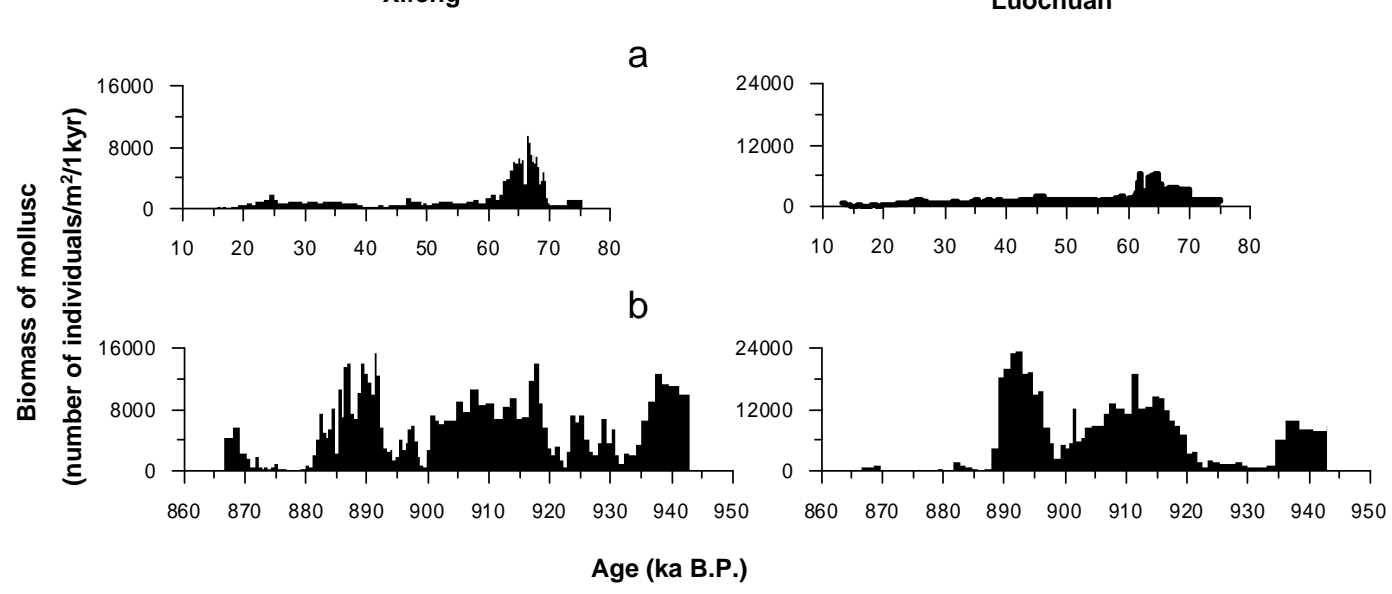

Fig. 6. Comparison of biomass of mollusc fossils from L1 (a) and L9 (b) records in the Xifeng and Luochuan loess sequences.

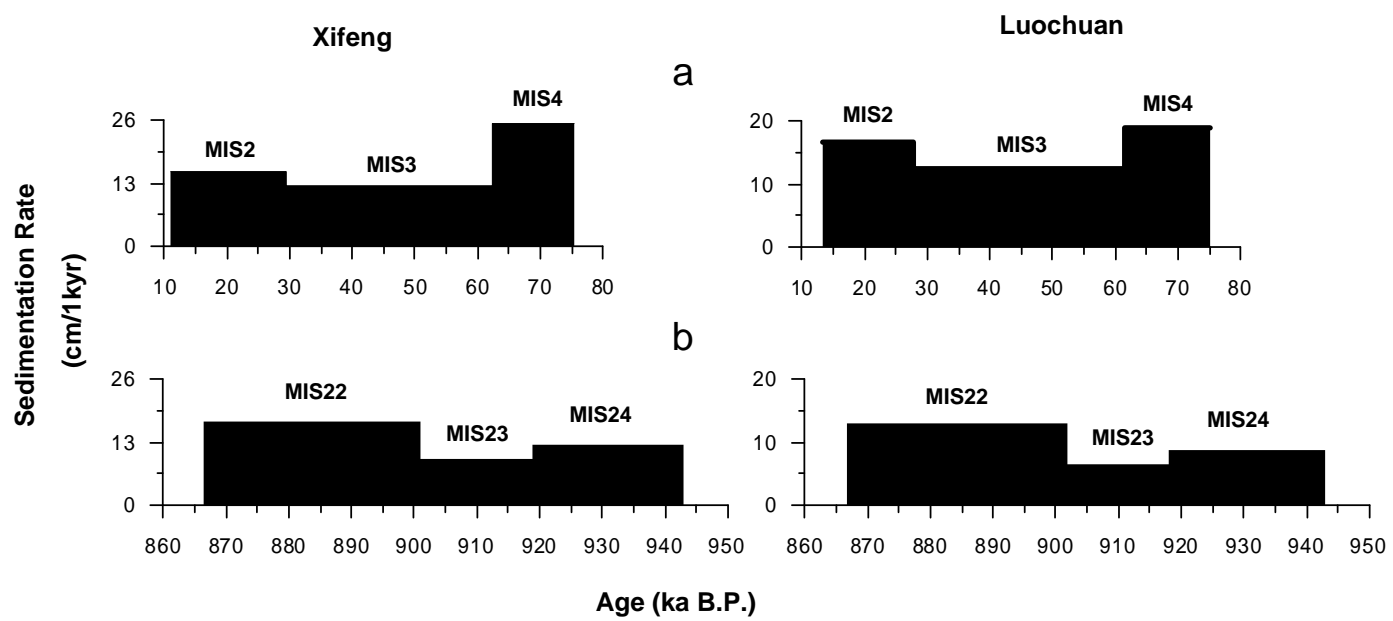

Fig. 7. Comparison of sedimentation rates from L1 (a) and L9 (b) records in the Xifeng and Luochuan loess sequences.

2003; Liu and Herbert, 2004; Raymo et al., 2004; Schefuss et al., 2004; McClymont and Rosell-Mele, 2005; Jin et al., 2009). All records with different resolutions indicated that the cooling mainly happened at MIS 24 and 22. However, the timing and amplitude of major temperature drops are significantly different in various records. For example, North Atlantic SSTs dropped to the lowest value at MIS 22 with an amplitude of $\sim 10^{\circ} \mathrm{C}$ (Ruddiman et al., 1989), while in eastern equatorial Pacific SSTs fell only by $\sim 2^{\circ} \mathrm{C}$ at MIS 22 and $4{ }^{\circ} \mathrm{C}$ at MIS 24 (Liu and Herbert, 2004). Although work to date has revealed many strong hints of this event in both marine and terrestrial records, its pattern and regional responses have not been well understood.

In East Asia, biological records from the Lake Baikal and South China Sea indicated an intensified East Asian winter monsoon and remarkable decreases in temperature at $\sim 900$ ka (Williams et al., 1997; Jian et al., 2003; Zheng et al., 2005), apparently implying a prominent response of regional climate to the 900-ka cooling event. In the Chinese Loess Plateau, the thick L9 loess itself, which indicated a strengthened winter monsoon and increased Asia aridity (Liu, 1985; Guo et al., 1998; Lu et al., 2000; Sun et al., 2006), was suggested to be linked to this event. In previous studies, the L9 loess as a whole was correlated to the "900-ka event" (e.g. Clark et al., 2006). However, our mollusc records from the Xifeng and Luochuan loess sequences reveal that climatic conditions in the Loess Plateau were not stable during this interval (MIS 24-22). This interval generally with cold conditions together with strong winter monsoon, suggested by dominant cold-aridiphilous mollusc taxa in both sections, was interrupted by two warm episodes associated with strengthened summer monsoon. These two obvious warm episodes occurred at $\sim 920 \mathrm{ka}$ and $\sim 895 \mathrm{ka}$. It is evident that the 900-ka cooling event in the Loess Plateau started at $\sim 940 \mathrm{ka}$ and experienced three cooling fluctuations at $\sim 930 \mathrm{ka}, 900 \mathrm{ka}$ and $880 \mathrm{ka}$. Among them, the one at 
$\sim 900 \mathrm{ka}$ (the boundary of MIS 23 and 22) was the toughest in both intensity and extent, but its duration is the shortest (Fig. 4). This cold stage started with a fast cooling and ended with a rapid warming, and it is characterised by extremely cold-dry climatic conditions, as mentioned above. The unstable climatic conditions during MIS 24-22 suggest that the 900-ka event in the Loess Plateau is not a simple long glaciation, but a complex of several fluctuations in temperature superposed on a general cooling trend.

\subsection{Possible causes of the formation of exceptionally thick and coarse-grained L9 loess}

The grain size variations in numerous loess sections show that the loess unit L9 and L15 represent the coarsest loess of the last 2.5 Ma (Liu and Ding, 1993). The question here is why was the exceptionally thick and coarse loess deposition of L9 accumulated during the gentle glaciation of MIS 24-22. One reason is that abundant dust sources and fast dust accumulation occurred during this period. It is commonly considered that desertic lands in northwestern China and central Asia are the source areas of loess, and the dust is transported by northwesterly winter monsoon winds (Liu, 1985; An et al., 1991). Sun and Liu (2000) thought that the uplift of Tibetan Plateau and its adjacent regions between 1.1-0.9 Ma greatly favoured the production of aeolian dust through its control on the glacial erosion and mountain denudation, thus, resulting in a rapid increase of source materials of desert and loess. Recently, another new explanation suggested by Lu et al. (2010) was that the general cooling experienced by the Earth during MPT might also strengthen high-mountain weathering and intensify the Asian winter monsoon circulations, which in turn caused an increase of general dust transport capability. What the cause of the thick L9 loess formation was, still need more work to testify in the future.

Another reason is the climatic conditions of the subdued interglacial of MIS 23. The preservation and assemblages of mollusc fossil together with other proxies (Kukla and An, 1989; Guo et al., 2000; Sun et al., 2006) all indicate mild climatic conditions during MIS 23. Relatively cool climatic conditions of MIS 23 brought about relatively weak pedogenic characteristic of L9SS1 paleosol. This is why the paleosol unit of L9SS1 and two typical loess units of L9LL1 and L9LL2 are usually incorporated into a complex unit of L9 loess in field work, leading to the prominent thickness of L9.

\section{Conclusions}

The study of land snail records from two loess sequences of the Chinese Loess Plateau provides reliable and detailed information about climatic implications of L9 loess. Our results show that the L9 loess developed under variable climatic conditions. Generally cold and dry climate dominated the main stage of MIS 24 and early and late parts of MIS 22 . Episodes of relatively mild-humid climate occurred during MIS 23 and middle part of MIS 22. Climatic conditions at Xifeng were more severe and instable than at Luochuan, reflecting an obvious regional difference in the impacts of East Asian summer monsoon on the Loess Plateau.

Comparisons of L9 and L1 loess layers based on mollusc assemblages and other climate proxies show that the climatic conditions recorded by L9 loess were not the most severe in the Quaternary history, similar to those indicated by marine isotope records. Therefore, climatic changes revealed by L9 loess not only have regional signals, but also have a global comparable significance. Our mollusc records also reveal the pattern of climatic response in Loess Plateau to the $900-\mathrm{ka}$ global cooling event. It is characterised by three major cooling fluctuations occurring at $\sim 930 \mathrm{ka}, 900 \mathrm{ka}$ and $880 \mathrm{ka}$, respectively. Our study suggests that the 900-ka event is not a simple long glaciation, but a complex of several fluctuations with a generally cooling trend. The increase in dust source for loess associated with the uplift of the Tibetan Plateau and its adjacent regions, the increase in dust transport capability caused by the general cooling during MPT, and mild climatic conditions of the subdued interglacial of MIS 23 are potential causes for the formation of the unique thick L9 loess deposition.

\section{Supplementary material related to this \\ article is available online at: http://www.clim-past.net/7/349/2011/ cp-7-349-2011-supplement.pdf.}

Acknowledgements. This study is supported by the National Basic Research Program of China (2010CB950204), the National Natural Science Foundation of China (Projects 40972119 and 40672116), and the Chinese Academy of Sciences (KZCX2-YW-117). The authors are grateful to C. M. Shen and W. White for improving the language, Houyuan $\mathrm{Lu}$ and Fengjiang $\mathrm{Li}$ for their helpful discussions, and Fengjian Li, Xiaoyun Chen, Jianping Zhang, and Linpei Huang for field collaboration. Y. Sun, H. Lu and R. Oches are thanked for their constructive comments and helps in improving the manuscript.

Edited by: G. M. Ganssen

\section{References}

An, Z. S., Kukla, G., Porter, S. C. and Xiao, J. L.: Late Quaternary dust flow on the Chinese loess plateau, Catena, 18, 125-132, 1991.

Bintanja, R. and van de Wal, R. S. W.: North American ice-sheet dynamics and the onset of 100,000-year glacial cycles, Nature, 454, 869-872, 2008.

Chen, D. N. and Gao, J. X.: Economic Fauna Sinica of China, Terrestrial Mollusca, Science Press, Beijing, 186 pp., 1987. 
Chen, X. Y. and Wu, N. Q.: Relatively warm and humid climate record by mollusk species in the Chinese Loess Plateau during MIS 3 and its possible forcing mechanism, Quaternary Sci., 28, 154-161, 2008.

Clark, P. U., Archer, D., Pollard, D., Blum, J. D., Rial, J. A., Brovkin, V., Mix, A. C., Pisias, N. G., and Roy, M.: The middle Pleistocene transition: characteristics, mechanisms, and implications for long-term changes in atmospheric $p \mathrm{CO}_{2}$, Quaternary Sci. Rev., 25, 3150-3184, 2006.

Clemens, S. C., Murray, D. W., and Prell, W. L.: Nonstationary phase of the plio-pleistocene Asian monsoon, Science, 274, $943-$ 948, 1996

Ding, Z. L., Derbyshire, E., Yang, S. L., Yu, Z. W., Xiong, S. F., and Liu, T. S.: Stacked 2.6-Ma grain size record from the Chinese loess based on five sections and correlation with the deep-sea $\delta^{18} \mathrm{O}$ record, Paleoceanography, 17, 5.1-5.21, 2002.

Guo, Z. T., Fedoroff, N., and Liu, D. S.: Micromorphology of the loess-paleosol sequence of the last $130 \mathrm{ka}$ in China and paleoclimatic events, Sci. China Ser. D, 39, 468-477, 1996.

Guo, Z. T., Liu, T. S., Fedoroff, N., Wei, L. Y., Ding, Z. L., Wu, N. Q., Lu, H. Y., Jiang, W. Y., and An, Z. S.: Climate extremes in Loess of China coupled with the strength of deep-water formation in the North Atlantic, Global Planet. Change, 18, 113-128, 1998.

Guo, Z. T., Biscaye, P., Wei, L. Y., Chen, X. H., Peng, S. Z., and Liu, T. S.: Summer monsoon variations over the last $1.2 \mathrm{Ma}$ from the weathering of loess-soil sequences in China, Geophys. Res. Lett., 27, 1751-1754, 2000 .

Heller, F. and Liu, T. S.: Magnetostratigraphical dating of loess deposits in China, Nature, 300, 431-433, 1982.

Heller, F., Shen, C. D., Beer, J., Liu, X. M., Liu, T. S., Bronger, A., Suter, M. and Bonani, G.: Quantitative estimates of pedogenic ferromagnetic mineral formation in Chinese loess and paleoclimatic implications, Earth Planet. Sc. Lett., 114, 385-390, 1993.

Hodell, D. A., Venz, K. A., Charles, C. D., and Ninnemann, U. S.: Pleistocene vertical carbon isotope and carbonate gradients in the South Atlantic sector of the Southern Ocean, Geochem. Geophy. Geosy., 4, 1004, 2003.

Jansen, E., Fronval, T., Rack, F., and Channell, J. E. T.: PliocenePleistocene ice rafting history and cyclicity in the Nordic Seas during the last 3.5 Myr, Paleoceanography, 15, 709-721, 2000.

Jian, Z. M., Zhao, Q. H., Cheng, X. R., Wang, J. L., Wang, P. X., and $\mathrm{Su}, \mathrm{X}$.: Pliocene-Pleistocene stable isotope and paleoceanographic changes in the northern South China Sea, Palaeogeogr. Palaeocl., 193, 425-442, 2003.

Jin, Z. D., Bickle, M. J., Chapman, H. J., Yu, J. M., Wang, S. M., and Chen, S. Y.: Early to mid-Pleistocene ostracod $\delta^{18} \mathrm{O}$ and $\delta^{13} \mathrm{C}$ in the central Tibetan Plateau: Implication for Indian monsoon change, Palaeogeogr. Palaeocl., 280, 406-414, 2009.

John, K. E. K. S. and Krissek, L. A.: The late Miocene to Pleistocene ice-rafting history of southeast Greenland, Boreas, 31, 28-35, 2002.

Kitamura, A. and Kawagoe, T.: Eustatic sea-level change at the Mid-Pleistocene climate transition: new evidence from the shallow-marine sediment record of Japan, Quaternary Sci. Rev., 25, 323-335, 2006.

Kukla, G.: Loess stratigraphy in Central China, Quaternary Sci. Rev., 6, 191-219, 1987.
Kukla, G. and An, Z. S.: Loess stratigraphy in Central China, Palaeogeogr. Palaeocl., 72, 203-225, 1989.

Kukla, G., An, Z. S., Melice, J. L., Gavin, J., and Xiao, J. L.: Magnetic susceptibility record of Chinese loess, T. Roy. Soc. EdinEarth., 81, 263-288, 1990.

Lisiecki, L. E. and Raymo, M. E.: A Pliocene-Pleistocene stack of 57 globally distributed benthic $\delta^{18} \mathrm{O}$ records, Paleoceanography, 20, PA1003, doi:10.1029/2004PA001071, 2005.

Liu, T. S.: Loess and the Environment, China Ocean Press, Beijing, 251 pp., 1985.

Liu, T. S. and Ding, Z. L.: Stepwise coupling of monsoon circulations to global ice volume variations during the late Cenozoic, Global Planet. Change, 7, 119-130, 1993.

Liu, T. S., Guo, Z. T., Liu, J. Q., Han, J. M., Ding, Z. L., Gu, Z. Y., and Wu, N. Q.: Variations of eastern Asian monsoon over the last 140,000 years, B. Soc. Geol. Fr., 166, 221-229, 1995.

Liu, T. S., Ding, Z. L., and Rutter, N.: Comparison of Milankovitch periods between continental loess and deep sea records over the last 2.5 Ma, Quaternary Sci. Rev., 18, 1205-1212, 1999.

Liu, Z. H. and Herbert, T. D.: High-latitude influence on the eastern equatorial Pacific climate in the early Pleistocene epoch, Nature, 427, 720-723, 2004.

Lu, H. Y., van Huissteden, K., Zhou, J., Vandenberghe, J., Liu, X. D., and An, Z. S.: Variability of East Asian winter monsoon in Quaternary climatic extremes in North China, Quaternary Res., 54, 321-327, 2000.

Lu, H., Wang, X., and Li, L.: Aeolian sediment evidence that global cooling has driven late Cenozoic stepwise aridification in central Asia, Geol. Soc. Sp., 342, 29-44, 2010.

McClymont, E. L. and Rosell-Mele, A.: Links between the onset of modern Walker circulation and the mid-Pleistocene climate transition, Geology, 33, 389-392, 2005.

Mudelsee, M. and Schulz, M.: The Mid-Pleistocene climate transition: onset of $100 \mathrm{ka}$ cycle lags ice volume build-up by $280 \mathrm{ka}$, Earth Planet. Sc. Lett., 151, 117-123, 1997.

Porter, S. C. and An, Z. S.: Correlation between climate events in the North Atlantic and China during the last glaciation, Nature, 375, 305-308, 1995.

Puisségur, J. J.: Mollusques continentaux quaternaries de Bourgogne. Significations stratigraphiques et climatiqus, Rapports avec d'autres faunes boréales de France, M'emoires G'eologiques de l'Universit'e de Dijon, Centre de paléogéographie et de paléobiologie evolutives, Dijon, 241 pp., 1976.

Raymo, M. E., Oppo, D. W., and Curry, W.: The mid-Pleistocene climate transition: A deep sea carbon isotopic perspective, Paleoceanography, 12, 546-559, 1997.

Raymo, M. E., Oppo, D. W., Flower, B. P., Hodell, D. A., McManus, J. F., Venz, K. A., Kleiven, K. F., and McIntyre, K.: Stability of North Atlantic water masses in face of pronounced climate variability during the Pleistocene, Paleoceanography, 19, PA2008, doi:10.1029/2003PA000921, 2004.

Rousseau, D. D. and Wu, N. Q.: A new molluscan record of the monsoon variability over the past $130000 \mathrm{yr}$ in the Luochuan loess sequence, China, Geology, 25, 275-278, 1997.

Rousseau, D. D. and Wu, N. Q.: Mollusk record of monsoon variability during the L2-S2 cycle in the Luochuan Loess sequence, China, Quaternary Res., 52, 286-292, 1999. 
Rousseau, D.-D., Wu, N., Pei, Y., and Li, F.: Three exceptionally strong East-Asian summer monsoon events during glacial times in the past $470 \mathrm{kyr}$, Clim. Past, 5, 157-169, doi:10.5194/cp-5157-2009, 2009.

Ruddiman, W., Raymo, M., Martinson, D., Clement, B., and Backman, J.: Pleistocene evolution: Northern Hemisphere ice sheets and North Atlantic Ocean, Paleoceanography, 4, 353-412, 1989.

Schefuss, E., Damste, J. S. S., and Jansen, J. H. F.: Forcing of tropical Atlantic sea surface temperatures during the mid-Pleistocene transition, Paleoceanography, 19, PA4029, doi:10.1029/2003PA000892, 2004.

Sun, J. M. and Liu, T. S.: Stratigraphic evidence for the uplift of the Tibetan Plateau between 1.1 and 0.9 myr ago, Quaternary Res., 54, 309-320, 2000.

Sun, Y. B., Clemens, S. C., An, Z. S., and Yu, Z. W.: Astronomical timescale and palaeoclimatic implication of stacked 3.6-Myr monsoon records from the Chinese Loess Plateau, Quaternary Sci. Rev., 25, 33-48, 2006.

Williams, D. F., Peck, J., Karabanov, E. B., Prokopenko, A. A., Kravchinsky, V., King, J., and Kuzmin, M. I.: Lake Baikal record of continental climate response to orbital insolation during the past 5 million years, Science, 278, 1114-1117, 1997.

Wu, F. L., Fang, X. M., Ma, Y. Z., An, Z. S., and Li, J. J.: A $1.5 \mathrm{Ma}$ sporopollen record of paleoecologic environment evolution in the central Chinese Loess Plateau, Chinese Sci. Bull., 49, 295-302, 2004.
Wu, N. Q., Rousseau, D. D., and Liu, D. S.: Land mollusk records from the Luochuan loess sequence and their paleoenvironmental significance, Sci. China Ser. D, 39, 494-502, 1996.

Wu, N. Q., Rousseau, D. D., and Liu, D. S.: Climatic instability recorded by the mollusk assemblages from the late glacial loess deposits in China, Chinese Sci. Bull., 44, 1238-1242, 1999.

Wu, N. Q., Rousseau, D. D., and Liu, X. P.: Response of mollusk assemblages from the Luochuan loess section to orbital forcing since the last $250 \mathrm{ka}$, Chinese Sci. Bull., 45, 1617-1622, 2000.

Wu, N. Q., Rousseau, D. D., Liu, T. S., Lu, H. Y., Gu, Z. Y., Guo, Z. T., and Jiang, W. Y.: Orbital forcing of terrestrial mollusks and climatic changes from the Loess Plateau of China during the past 350 ka, J. Geophys. Res.-Atmos., 106, 20045-20054, 2001.

Wu, N. Q., Liu, T. S., Liu, X. P., and Gu, Z. Y.: Mollusk record of millennial climate variability in the Loess Plateau during the Last Glacial Maximum, Boreas, 31, 20-27, 2002.

Wu, N. Q., Chen, X. Y., Rousseau, D. D., Li, F. J., Pei, Y. P., and Wu, B.: Climatic conditions recorded by terrestrial mollusc assemblages in the Chinese Loess Plateau during marine oxygen isotope Stages 12-10, Quaternary Sci. Rev., 26, 1884-1896, 2007.

Zhang, J. C. and Liu, Z. G.: Climate of China, Wiley, New York, 376 pp., 1992.

Zheng, F., Li, Q. Y., Li, B. H., Chen, M. H., Tu, X., Tian, J., and Jian, Z. M.: A millennial scale planktonic foraminifer record of the mid-Pleistocene climate transition from the northern South China Sea, Palaeogeogr. Palaeocl., 223, 349-363, 2005. 